\title{
Diesel Exhaust Emissions Control for Light Duty Vehicles
}

R. Mital, J. Li, S. C. Huang, B. J. Stroia and R. C. Yu Cummins, Inc.

J. A. Anderson Argonne National Laboratory

Kenneth Howden U. S. Department of Energy 
All rights reserved. No part of this publication may be reproduced, stored in a retrieval system, or transmitted, in any form or by any means, electronic, mechanical, photocopying, recording, or otherwise, without the prior written permission of SAE.

For permission and licensing requests contact:

SAE Permissions
400 Commonwealth Drive
Warrendale, PA 15096-0001-USA
Email: permissions @ sae.org
Fax: $\quad 724-772-4028$
Tel: $\quad 724-772-4891$

Tel: $\quad 724-772-4891$

For multiple print copies contact:

SAE Customer Service

Tel: $\quad$ 877-606-7323 (inside USA and Canada)

Tel: $\quad$ 724-776-4970 (outside USA)

Fax: $\quad$ 724-776-1615

Email: CustomerService@sae.org

\section{ISSN 0148-7191}

\section{Copyright $\odot 2003$ SAE International}

Positions and opinions advanced in this paper are those of the author(s) and not necessarily those of SAE. The author is solely responsible for the content of the paper. A process is available by which discussions will be printed with the paper if it is published in SAE Transactions.

Persons wishing to submit papers to be considered for presentation or publication by SAE should send the manuscript or a $\mathbf{3 0 0}$ word abstract of a proposed manuscript to: Secretary, Engineering Meetings Board, SAE.

\section{Printed in USA}




\title{
Diesel Exhaust Emissions Control for Light Duty Vehicles
}

\author{
R. Mital, J. Li, S. C. Huang, B. J. Stroia and R. C. Yu \\ Cummins, Inc. \\ J. A. Anderson \\ Argonne National Laboratory \\ Kenneth Howden \\ U. S. Department of Energy
}

Copyright @ 2003 SAE International

\begin{abstract}
The objective of this paper is to present the results of diesel exhaust aftertreatment testing and analysis done under the FreedomCAR program. Nitrogen Oxides (NOx) adsorber technology was selected based on a previous investigation of various NOx aftertreatment technologies including non-thermal plasma, NOx adsorber and active lean NOx. Particulate Matter (PM) emissions were addressed by developing a catalyzed particulate filter. After various iterations of the catalyst formulation, the aftertreatment components were integrated and optimized for a light duty vehicle application.

This compact exhaust aftertreatment system is dual leg and consists of a sulfur trap, NOx adsorbers, and catalyzed particulate filters (CPF). During regeneration, supplementary ARCO ECD low-sulfur diesel fuel is injected upstream of the adsorber and CPF in the exhaust. Steady state and transient emission test results with and without the exhaust aftertreatment system (EAS) are presented. Results of soot filter regeneration by injecting low-sulfur diesel fuel and slip of unregulated emissions, such as $\mathrm{NH}_{3}$, are discussed. Effects of adsorber size and bypass strategy on $\mathrm{NO}_{x}$ conversion efficiency and fuel economy penalty are also presented in this paper. The results indicate that if the supplementary fuel injection is optimized, $\mathrm{NH}_{3}$ slip is negligible. During the FTP cycle, injection of low sulfur diesel fuel can create temperature exotherms high enough to regenerate a loaded CPF. With the optimized NOx adsorber regeneration strategies the fuel injection penalty can be reduced by 40 to $50 \%$. Results for various other issues like low temperature light off, reductant optimization, exhaust sulfur management, system integration and design trade-off, are also presented and discussed in this paper.
\end{abstract}

\section{INTRODUCTION}

Due to their excellent fuel efficiency, reliability, and durability, compression ignition direct injection (CIDI) engines have been used extensively to power almost all highway trucks, urban buses, off-road vehicles, marine carriers, and industrial equipment. CIDI diesel engines burn 35 to $50 \%$ less fuel than gasoline engines of comparable size, and they emit far less greenhouse gases (Carbon dioxides), which have been implicated in global warming. Although the emissions of CIDI diesel engines have been reduced significantly over the last decade, there remains concern with the NOx and PM emissions levels. In 2000, the US EPA proposed very stringent emissions standards to be introduced in 2007 along with low sulfur (< 15 PPM) diesel fuel. The California Air Resource Board (CARB) has also established the principle that future diesel fueled vehicles should meet the same low emissions standards as gasoline fueled vehicles and the EPA followed suit with its Tier II emissions regulation.

Meeting the Tier II standards requires NOx and PM emissions to be reduced significantly. Achieving such low emissions cannot be done through engine development and fuel reformulation alone, and requires application of NOx and PM aftertreatment control devices. This paper provides a summary of the study of an integrated engine and aftertreatment system for achieving very low vehicle-out emissions while maintaining the superior advantages of CIDI on fuel efficiency, reliability, and durability.

\section{EMISSION STANDARDS AND TEST CYCLE DEFINITION}

Based on EPA's Tier 2 emission standards that will be phased-in between 2004 and 2009, vehicles are classified based on gross vehicle weight rating (GVWR), and their applications. Passenger cars and light-duty trucks with GVWR less than 8500 lb. are tested on 
chassis dynamometer using FTP-75 cycle and Supplemental Federal Test Procedure (SFTP). Heavyduty vehicles with GVWR above $8500 \mathrm{lb}$. are tested on engine dynamometer using FTP Heavy Duty (HD) cycle and Supplemental Emission Test (SET). Medium-duty passenger vehicles (MDPV) for GVWR up to $14,000 \mathrm{lb}$. can be optionally tested using either light-duty standards or heavy-duty standards.

FTP-75 cycle specifies the vehicle speed over time, and emission standards in $\mathrm{g} / \mathrm{mile}$. Three phases are included in this cycle: 0-505 sec cold transient, 506-1372 sec cold stabilized, and 0-505 sec hot transient. The hot transient phase is a repeat test of the cold transient phase, but with a 10-min soak period following the cold stabilized phase. Emissions from cold and hot start are combined using the weighting factors of 0.43 and 0.57 , respectively, with an assumption that the stabilized cold phase will have the same emissions as the hot start. Following Tier 2 standards, vehicle manufactures will have a choice to certify a specific vehicle to any of the 8 bins of different stringency. However, the entire vehicle fleet sold by each manufacturer will have to meet the average NOx and PM standards of $0.07 \mathrm{gm} / \mathrm{mile}$ and $0.01 \mathrm{gm} / \mathrm{mile}$ respectively.

US HD cycle specifies the normalized engine speed and torque history with respect to full-throttle torque curve, and the emission standards in $\mathrm{g} / \mathrm{bhp}-\mathrm{hr}$. There is a 20-min cold start transient cycle, followed by a repeat 20-min hot start transient cycle after a 20-min soak period. Unlike FTP-75 cycle, the cold start emission has a much lower weighting factor, $1 / 7$ vs. $6 / 7$, for the hot start cycle. For US HD transient cycle, the NOx and PM standards of $0.2 \mathrm{gm} / \mathrm{bhp}-\mathrm{hr}$ and $0.01 \mathrm{gm} / \mathrm{bhp}-\mathrm{hr}$ respectively, will be phased in between 2007 and 2010 . Additionally, SET emission test using Euro III cycle will be met against the same FTP standard, and Not-toExceed (NTE) to meet 1.5 times the FTP standards.

\section{APPROACH}

Under this study, various aftertreatment technologies including NOx absorbers, catalyzed particulate filter, and sulfur trap, in conjunction with active reductant injection were investigated and developed for emission control subsystem integration and development [1]. The areas of NOx adsorber development include catalyst formulation for high conversion over an increased catalyst/exhaust gas temperature range, catalyst structure for increased exhaust gas residence time on active catalyst sites, and an understanding of the various factors that cause deactivation of the catalyst. Fuel reformulation concepts were investigated to increase the activity of the hydrocarbons introduced into the catalyst systems. Even with the availability of $15 \mathrm{ppm}$ sulfur fuels, the development of a sulfur management scheme is critical to prevent catalyst poisoning and deactivation. The application of a sulfur trap that can be regenerated offline or periodically replaced was explored.

PM emissions were addressed by developing a CPF. The key areas of development include developing catalyst formulation with improved low temperature performance, exploring synergies between particulate and NOx aftertreatment strategies, and determining the need for supplemental heating. A supplemental heating system may be required to help the CPF get through those portions of the duty cycle where temperature is too low to achieve a high rate of particulate burning to prevent soot accumulation.

Finally, the improved aftertreatment components were integrated and configured optimally in a system developed for a light duty application. This system was calibrated and tested in a controlled environment on a light duty sized engine.

\section{AFTERTREATMENT DEVICE FUNDAMENTAL AND FORMULATION DEVELOPMENT}

NOx adsorber technology relies on removal of NOx from the exhaust under lean conditions by adsorption [2]. This is followed by periodic regeneration of the adsorbent along with reduction of the released NOx under rich conditions. This alleviates the need for maintaining a given $\mathrm{C} 1 / \mathrm{NOx}$ ratio under transient and fluctuating exhaust NOx levels, as in the case of the lean NOx catalyst. For current state-of-the-art catalysts the lean adsorption step entails the reaction of an acidic gas $\left(\mathrm{NO}_{2}\right)$ with a basic adsorbent (alkaline earth oxide, e.g. $\mathrm{BaO}$ ) to form a nitrate or nitro-species. Since engine-out $\mathrm{NOx}$ is primarily $(90 \%) \mathrm{NO}$ it must first be oxidized to $\mathrm{NO}_{2}$ over a Pt-based catalyst. The results indicate that $\mathrm{Pt} / \mathrm{Base}$ Metal Oxide (BMO) intimate contact is essential for higher NOx trapping capacity. When the effective capacity of the adsorber is reached, the NOx is released by a pulsed introduction of hydrocarbon $(\mathrm{HC})$ reductant (e.g. diesel fuel) enough to establish a rich environment and under this condition the NOx is reduced to $\mathrm{N}_{2}$ over a conventional three-way catalyst. Nitrate or adsorbed $\mathrm{NO}_{2}$ can decompose and desorb from BMO thermodynamically, and it is $\mathrm{O}_{2}$ partial pressure dependent. NOx can also desorb by $\mathrm{HC}$ displacement, partially due to incomplete reduction. Trapped $\mathrm{NO}_{2}$ can totally desorb in the absence of $\mathrm{O}_{2}$ at $450 \mathrm{deg} \mathrm{C}$. The Pt/BMO interface is essential for NOx reduction to $\mathrm{N}_{2}$ with reductants during rich operation. No reduction of trapped NOx was observed on BMO without $\mathrm{Pt}$. Experimentally it was determined that the reductant quantity, at least 2 times of stoichiometry of $\mathrm{CH}_{2}$ is needed for full regeneration, and insufficient reductant leads to NO formation. Trapped NOx quantity also affects the NOx reduction, loosely trapped NOx species tend to release as NO during regeneration. The reduction reaction is kinetic controlled. It depends on reductant type, reduction temperature, especially at low temperature (e.g. $<250$ deg C), and reduction time.

With regard to PM control technology, CPF has been successfully formulated for HD diesel application, which achieves passive regeneration. Nevertheless, the passive filter regeneration is not robust, especially in cold climates. Typically, application screening must be performed prior to installing the particulate filter on the vehicle, and at least $10 \%$ of the duty cycle must be spent with filter inlet temperatures above $315 \mathrm{C}$. In addition, 
one must balance between particulate loading rate, engine duty cycle, filter size, and ambient temperature.

Another characteristic of passive regeneration of particulate filters is uncontrolled regeneration. Uncontrolled regeneration of particulate filters can occur when the filter is loaded with particulates, and undergoes an event during the duty cycle that initiates particulate combustion in the filter. After the particulate begins to combust, if the duty cycle is such that the vehicle goes to a stop, idle, or engine motoring condition, producing a low flow exhaust condition, the filter may overheat, and uncontrolled regeneration and subsequent filter failure will occur. The main factors that influence uncontrolled regeneration of particulate filters include: particulate loading level, exhaust temperature, exhaust flow, $\mathrm{O}_{2}$ concentration, $\mathrm{NO}_{2}$ concentration, and catalyst formulation. Engine results have shown that low precious metal loaded filters are more prone to undergo uncontrolled regeneration than filters with high levels of precious metals. This is directly related to the slower particulate burning rates associated with low precious metal loaded filters.

Critical experiments were designed to investigate the selected CPF system further. An advanced catalyzed particulate filter was tested with a precat upstream to evaluate the advantage of $\mathrm{NO}$ to $\mathrm{NO}_{2}$ function and catalyst exotherm in terms of balance point temperature (BPT). The precat with the advanced CPF gave a 40 to $50 \mathrm{C}$ reduction in the balance point temperature and better regeneration performance. The benefits of using a catalytic system for particulate filter regeneration are many: it is a relatively simple system, low cost, and has synergistic opportunities with the rest of the aftertreatment system. For instance, the CPF can be placed downstream of the NOx adsorber to make use of the heat generated during regeneration of the NOx adsorber. In this configuration, the CPF can also make use of the $\mathrm{HC}$ slip across the NOx adsorber, which will cause an additional exotherm with the CPF itself.

\section{EXHAUST SULFUR MANAGEMENT}

The NOx adsorber catalysts have achieved high NOx reduction levels using very low sulfur $(<3 \mathrm{ppm})$ diesel fuels. However, the degradation of adsorber performance due to sulfur poisoning remains an issue and needs to be addressed [3,4]. SOx competes for active NOx adsorption sites to form thermodynamically stable compounds that require an extremely high temperature $(>650 \mathrm{C}$ ) and reductant to regenerate the adsorber. The testing indicate that even with the availability of $15 \mathrm{ppm}$ sulfur diesel fuels, an effective exhaust sulfur management scheme is required to keep emission control devices operating near their peak effectiveness.

There are two paths that are currently being explored for sulfur management: (1) the use of SOx trap that can be regenerated offline or replaced periodically, and (2) the use of diesel fuel and high temperature to desorb the sulfates from NOx adsorber. The Pros and Cons of each system are summarized below.
Disposable/Offline Regenerable

- High adsorption capacity for sulfur

- High selectivity toward sulfur adsorption

- No release of secondary emissions from trap

- Usable life of SOx trap is dependent on Sulfur level in fuel and lube oil

- Good protection of adsorber catalyst from sulfur poisoning during miss-fueling

- Good technology for light duty applications-small size, low cost, and limited useful life requirement

NOx Adsorber Desulfation Catalyst

- Integrated NOx trap and sulfur trap function on one catalyst, does not require separate SOx trap

- Requires on-board high temperature exhaust management to release sulfur from catalyst $(>600 \mathrm{C})$

- Additional fuel penalty will be incurred during desulfation process

- Desulfation involves release of secondary emissions hydrogen sulfide and/or sulfur dioxides

- Catalyst material development required compromise among NOx storage \& conversion, SOx storage \& release, and catalyst thermal durability etc.

\section{SYSTEM INTEGRATION AND DESIGN TRADE- OFF}

Issues related to design trade-off, such as, effect of catalyst size, effect of target air-fuel ratio, effect of lean time and effect of bypass strategy are discussed in the following.

\section{EFFECT OF CATALYST SIZE}

The effect of catalyst size on NOx conversion efficiency and fuel penalty for full flow (FF) regeneration was studied under the control-based strategy at steady state. In FF, the whole exhaust flows through the catalyst during lean as well as rich operation. Under control based strategy the catalyst is regenerated only when the efficiency falls below the target value. The catalyst inlet temperature was varied by changing the engine torque. The NOx concentration was different at each temperature and depended on engine calibration. The Figure 1 shows the effect of catalyst size on NOx conversion efficiency and fuel penalty. The testing was done on a $5.9 \mathrm{~L}$ mule engine and the NOx adsorber catalyst size was varied from $7 \mathrm{~L}$ to $21 \mathrm{~L}$. As shown, $10.5 \mathrm{~L}$ catalyst $(\sim 1.8$ times engine displacement) can achieve the same NOx conversion efficiency as catalysts of bigger volume. The fuel penalty is similar above 320 ${ }^{\circ} \mathrm{C}$ for all tested catalyst sizes. Below $320{ }^{\circ} \mathrm{C}$, fuel penalty becomes higher for smaller catalyst sizes. A $7 \mathrm{~L}$ NOx adsorber has the worst NOx conversion efficiency and fuel penalty, and is inadequate for the application. 


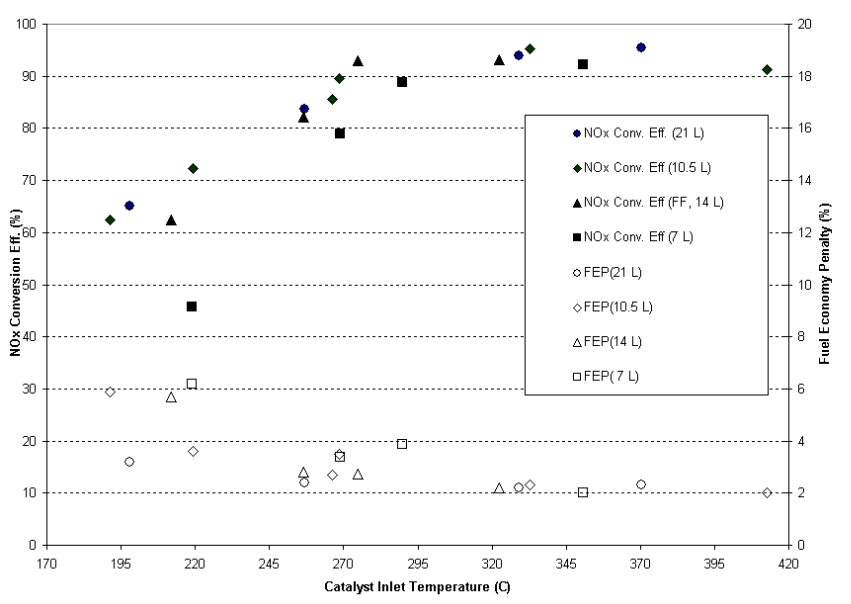

Fig 1 Effect of catalyst size under control-based regeneration at Steady State

\section{EFFECT OF A/F RATIO AND LEAN TIME}

Under steady-state engine operating conditions, the NOx adsorber is normally regenerated at fixed time intervals, for example, every 30 seconds. The quantity of the injected fuel has to be sufficient not only to produce rich conditions $(\lambda<1)$, but also to react with $\mathrm{NOx}$ desorbed from the catalyst and convert it into $\mathrm{N}_{2}[6]$. To ensure this condition is met, the injection quantity is usually based on a target air/fuel (A/F) ratio lower than stoichiometric (14.6 for diesel fuel), such as $A / F=9$. For diesel engines operating in oxygen rich exhaust conditions $(\lambda>1)$, a significant portion of the injected fuel is used to consume $\mathrm{O}_{2}$ in the exhaust. While laboratory tests have shown that a longer regeneration period can improve regeneration efficiency, this is usually not practical due to proportionally higher fuel penalty associated with the $\mathrm{O}_{2}$ reaction. For this reason, fuel injection is typically limited to produce only a very short rich period, for about 1 to 2 seconds. The effectiveness of the injected fuel to produce conditions favorable for NOx conversion depends on many factors, such as fuel atomization, injection quantity (A/F ratio) and flow distribution.



Figure 2 Effect of Target A/F Ratio
In this study, the NOx adsorber catalyst volume was 14 $L$ and the target $A / F$ ratio were varied from 9 to 13 to study its effect on NOx conversion efficiency. Figure 2 shows the effect of target A/F ratio on NOx conversion efficiency and fuel penalty at fixed 29-second lean and 1-second rich time. As shown, both NOx conversion efficiency and fuel penalty increase with decreasing $A / F$ ratio target. A/F ratio of 9 will be needed to achieve the high NOx conversion efficiency necessary to meet tier II emissions. The actual $\mathrm{A} / \mathrm{F}$ ratio was within $5 \%$ of target A/F ratio.

Figure 3 shows the NOx conversion efficiency using different lean times against varying catalyst inlet temperature. The target $A / F$ ratio is fixed at 9 for 1 second. As noted, high NOx conversion efficiency can be obtained by using either 29-second or 20-second lean time. But the latter has higher fuel penalty due to higher regeneration frequency. The NOx conversion efficiency starts to deteriorate when the lean time increases from $29 \mathrm{~s}$ to $40 \mathrm{~s}$.

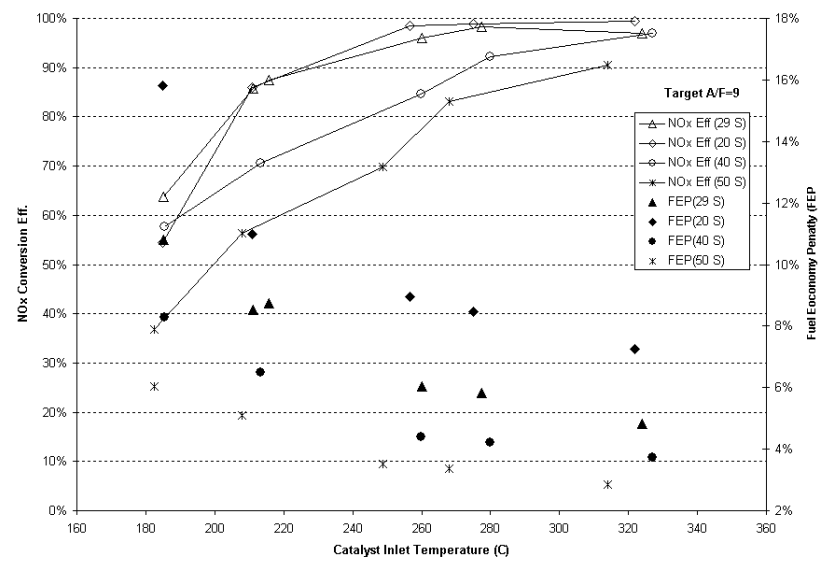

Figure 3 Effect of Lean Time

\section{BYPASS STRATEGY}

One way to reduce fuel penalty associated with NOx adsorber regeneration is to reduce $\mathrm{O}_{2}$ flow during regeneration. This can be accomplished by using the bypass configuration as shown in Figure 4 . In the full bypass (FB) system the flow after the SOx trap is split equally into two bypass legs. Each leg contains one-half of the total NOx adsorber volume, and each has a fuel injection system in front of the adsorber for regeneration. There is a CPF downstream after the two-leg combine. During regeneration, the flow through the adsorber under regeneration is restricted to below $50 \%$ of the total engine exhaust. For a fixed catalyst-in $\mathrm{A} / \mathrm{F}$ ratio target, the fuel injection required for regeneration can be proportionally reduced. For example, when $80 \%$ of the flow is bypassed during regeneration, the total fuel penalty is reduced by $60 \%$ when compared to full-flow regeneration. In addition, tests have shown that the $\mathrm{HC}$ slip after the NOx adsorber is also lower. This is because space velocity and fuel injection quantity are both lower during bypass, resulting in more complete reaction. 




Figure 4 Schematic of Full Bypass System

Testing under this program has confirmed that for the same NOx conversion efficiency the fuel penalty for FB is about $50 \sim 60 \%$ lower than for FF. In addition, the hydrocarbon slip from FB is much lower than FF because of the lower space velocity during regeneration period in FB system.

\section{TRANSIENT CVS TESTING}

The integrated aftertreatment system transient testing was carried out using the breadboard ISB $5.9 \mathrm{~L}$ engine in a CVS test cell. Simulated FTP-75 cycle was obtained from computer simulation and validated in chassis dynamometer tests of a typical Dodge Ram vehicle. Arco EC-D low sulfur $(<15 \mathrm{ppm})$ diesel fuel was used for both the breadboard ISB engine and the exhaust injection. A $7 \mathrm{~L} \mathrm{SOx}$ trap, two $14 \mathrm{~L} \mathrm{NOx}$ adsorbers and a 12.5 L CPF were arranged as shown in Figure 4. Two exhaust valves are used, one on each leg of the bypass system, to regulate the bypass flow. For the full flow configuration the adsorbers were arranged in series.

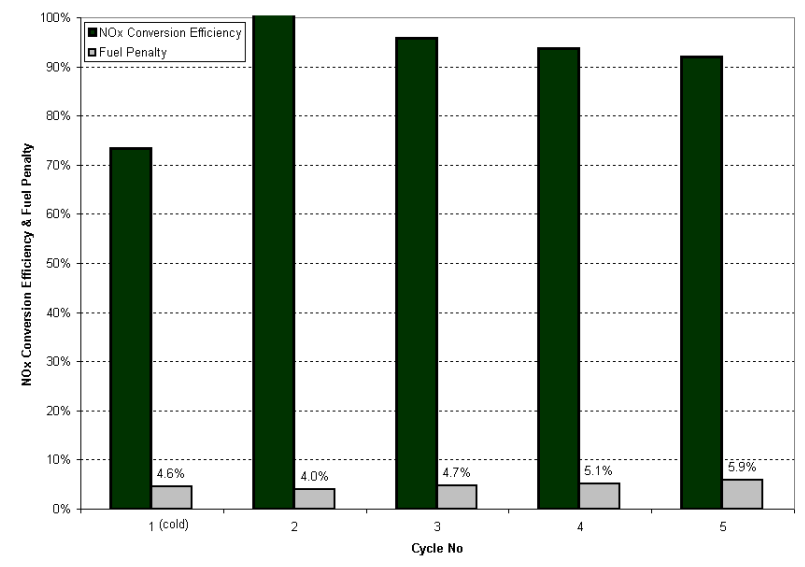

Figure 5 NOx conversion efficiency and fuel penalty for simulated FTP cycle

As compared to steady-state tests, transient tests provide some additional challenges. For example, the turbo out temperature is lower than the steady-state operation of the same engine speed and load due to engine thermal inertia. The effect of thermal inertia of the aftertreatment system also becomes more important, and further reduces the peak temperature at catalyst inlet. The initial state of the NOx adsorber is unknown at the beginning of each FTP-75 cycle. For steady-state tests, this can be overcome by a period of stabilized catalyst operation. It is impractical to pre-determine the regeneration timing and injection quantity, especially in real-world applications where the exhaust flow condition is varying continuously. Additionally, for bypass regeneration, the two catalysts can experience different inlet conditions (NOx rate, temperature, etc.), as well as different initial states.

A closed-loop regeneration control algorithm using various sensor inputs is implemented on a programmable controller. The regeneration timing and injection quantities are both dynamically determined by the controller during the transient test. To illustrate the impact of the initial state, the NOx adsorbers were first conditioned at a favorable steady-state condition (1400 $\mathrm{rpm}, 200 \mathrm{ft}-\mathrm{lb}$ ). Subsequent to the pre-conditioning, a hot FTP cycle was run without exhaust fuel injection. Over $90 \%$ NOx conversion efficiency can be obtained with no fuel penalty. However, this high efficiency can not be sustained. When the tests were repeated without pre-conditioning and regeneration, the NOx conversion efficiency dropped to around $70 \%$, and then $50 \%$, as the initial NOx loading at the beginning of each cycle became higher.

Since the NOx adsorber is a storage device, it is necessary to demonstrate the effectiveness of regeneration by maintaining the NOx conversion efficiency over several FTP cycles without preconditioning. The final state of these hot FTP cycles can be used to start the cold FTP-75 cycle the next day. Because of the low exhaust temperature, $72 \% \mathrm{NOx}$ conversion efficiency was obtained for the cold cycle (Figure 5). For subsequent hot FTP-75 cycles, the NOx conversion efficiency averaged about $87 \%$. The CPF particulate trapping efficiency averaged about $93 \%$. At about 200 seconds, there is a drop in the cumulative NOx efficiency because a period of high space velocity and high NOx loading occurs when the catalyst temperature is still relatively low. Subsequent regeneration slowly recovers the NOx conversion efficiency to the final value.

\section{CHASSIS DYNAMOMETER TESTING}

To evaluate the performance of an integrated aftertreatment system designed a for light duty vehicle, testing was conducted on the chassis-dynamometer at Argonne National laboratory (ANL). The full bypass $\mathrm{NO}_{x}$ adsorber system with exhaust injection was fitted to a Mercedes A170 vehicle, and several parameters including engine and tailpipe emissions, and catalyst efficiency were monitored. To prevent Sulfur poisoning, a sulfur trap upstream of the adsorbers was used during the testing in conjunction of the 15-ppm ARCO ECD low sulfur fuel. A catalyzed particulate filter (CPF) was used to reduce system-out particulates and hydrocarbon emissions (Figure 6). 


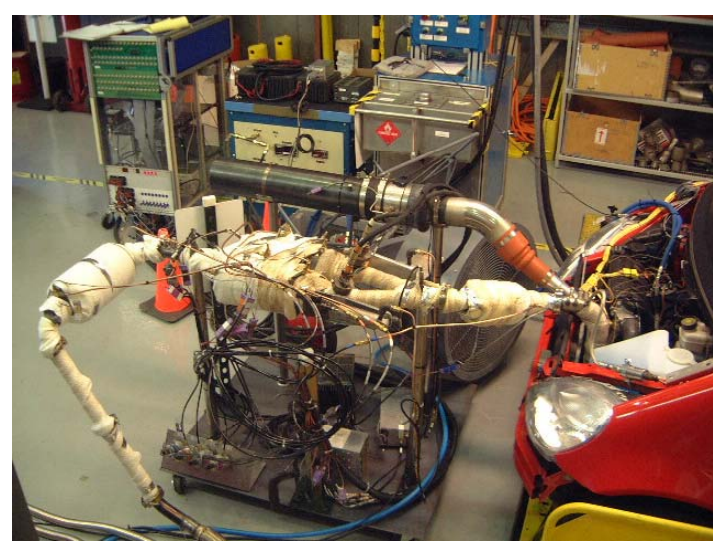

Figure 6 Full bypass EAS at ANL

To characterize the operation and efficiency of the catalyst system, every emissions bench within the Argonne lab was used. In total, a raw exhaust bench, two fast-response hydrocarbons, two fast-response nitric oxide, a particulate sampler, and a dilute bench with CVS were utilized. These emission measurement systems allowed for continuous monitoring of engine out emissions, catalyst efficiency, tailpipe out emissions and fuel consumption. The $\mathrm{A} 170$ is a $1.7 \mathrm{~L}$ engine and has about $0.9 \mathrm{~g} / \mathrm{mile}$ engine out NOx. Table 1 shows the catalyst volumes used in the EAS. The NOx adsorber catalyst volume to engine displacement was selected to be 1.8 based on the system design tradeoff critical experiment discussed earlier. The total catalyst volume to engine displacement was 4 . The baseline vehicle performance was evaluated first and is shown in Table 2. This was collected with additional 2" $\mathrm{Hg}$ backpressure to account for the EAS.

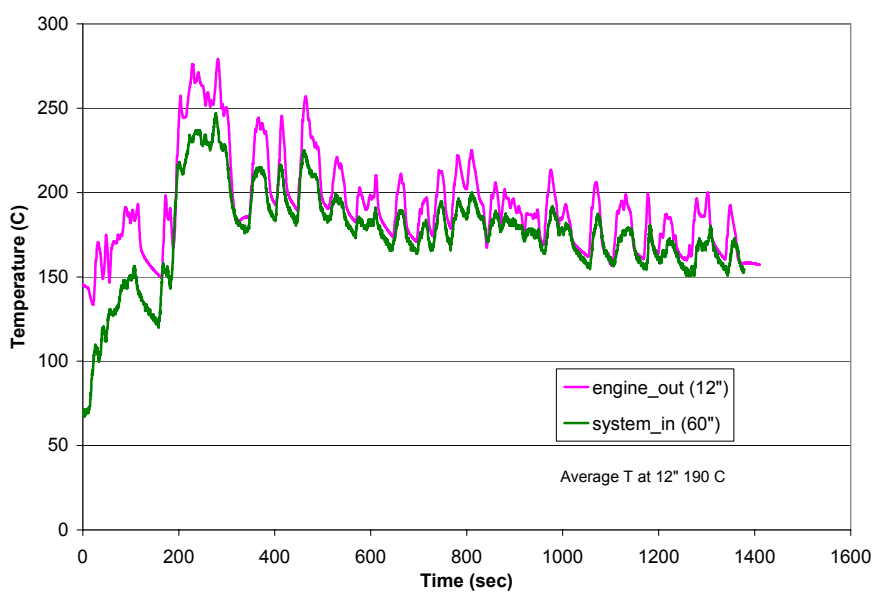

Figure 7 Temperature histories over UDDS cycle

The temperature history over the Urban Dynamometer Driving Schedule (UDDS) cycle is shown in Figure 7. As can be seen the temperature was very cold over the cycle, generally below $200 \mathrm{C}$. Various control algorithms and hardware were tested to obtain the best system performance. Glow plugs were used to simulate engine management for exhaust temperature enhancement. Different injectors with improved atomization were also tested.

Table 1

\begin{tabular}{|l|l|}
\hline Catalyst & Volume, $\mathbf{L}$ \\
\hline SOx & 1.25 \\
\hline Adsorber & 3.1 \\
\hline CPF & 2.5 \\
\hline Total & 6.85 \\
\hline
\end{tabular}

Table 2

\begin{tabular}{|l|l|l|l|l|l|}
\hline Cycle & $\mathbf{C O}$ & $\mathbf{C O}_{2}$ & THC & NOx & mpg \\
\hline UDDS & 1.28 & 223 & 0.081 & 0.957 & 44.9 \\
\hline HFET & 0.62 & 176 & 0.035 & 0.787 & 57.3 \\
\hline
\end{tabular}

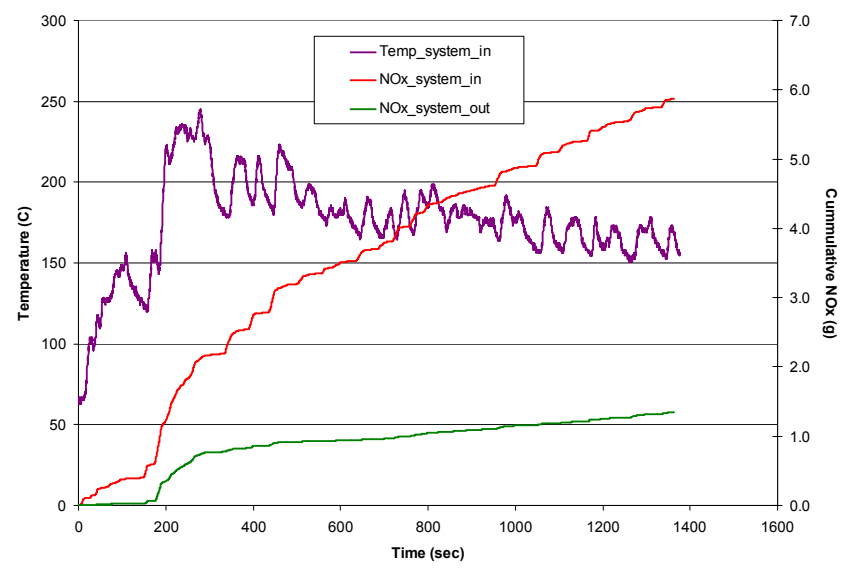

Figure 8 Representative UDDS cycle results

A representative UDDS cycle result is shown in Figure 8. The majority of the NOx slip from the aftertreatment system occurred around the 200-second hump in the UDDS cycle. A NOx conversion efficiency of $99 \%$ was obtained with a preconditioned catalyst. Preconditioning was done by running the vehicle at 65 miles per hour for 5 minutes while doing reductant injection. Without preconditioning a NOx conversion efficiency of $89 \%$ could be achieved at about $11.6 \%$ total fuel penalty for the FTP-72 cycle. The PM conversion was close to $99 \%$ and was beyond the detection capability of the measurement system at ANL.

Synergistic effects of NOx adsorbers and particulate filters were evaluated by attempting to regenerate CPF using $\mathrm{HC}$ injection. The initial steady state results (Figure 9) indicate that CPF can be regenerated using $\mathrm{HC}$ injection. At the start of the test the CPF was loaded (13" of water delta pressure). Hydrocarbon (diesel fuel) was injected upstream of the NOx adsorber which raised the system inlet temperature of $200{ }^{\circ} \mathrm{C}$ to almost $400{ }^{\circ} \mathrm{C}$ at CPF-in and the CPF was back to its originally clean condition in less than 10 minutes. 


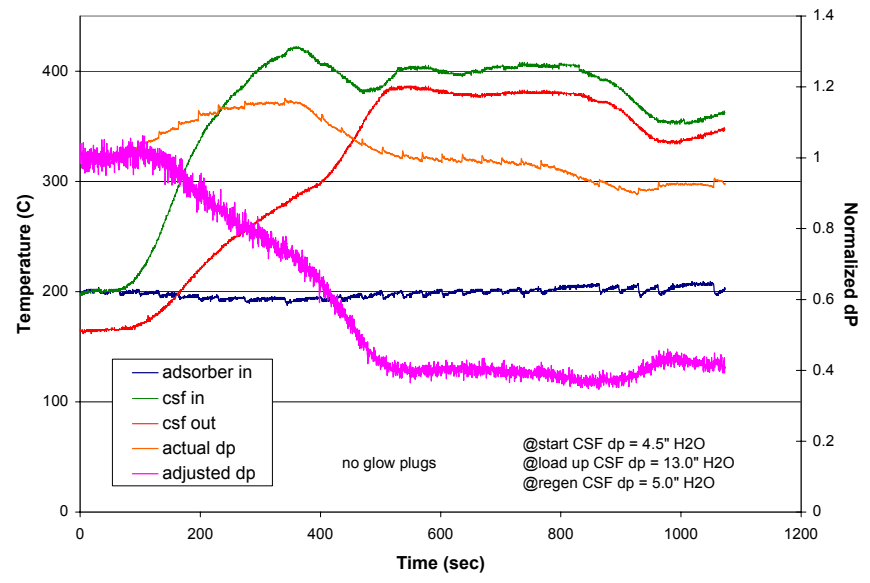

Figure 9. Catalyzed particulate filter regeneration using $\mathrm{HC}$ injection

There has been some speculation that $\mathrm{NH}_{3}$ is formed over the adsorber catalyst when $\mathrm{HC}$ is injected for cleaning up the stored NOx. A simulated cycle, which closely resembled the temperature distribution of an FTP-72 cycle, was run. When the reductant injection was too frequent (e.g. every 20 seconds) considerable amount of $\mathrm{NH}_{3}$ was formed with each injection. When the injection frequency was reduced (keeping the injection quantity per shot the same) the NOx conversion efficiency did not reduce substantially indicating more frequent injection was unnecessary fuel penalty. Excess $\mathrm{HC}$ was resulting in substantial $\mathrm{NH}_{3}$ formation and slip. This result is shown in Figure 10.

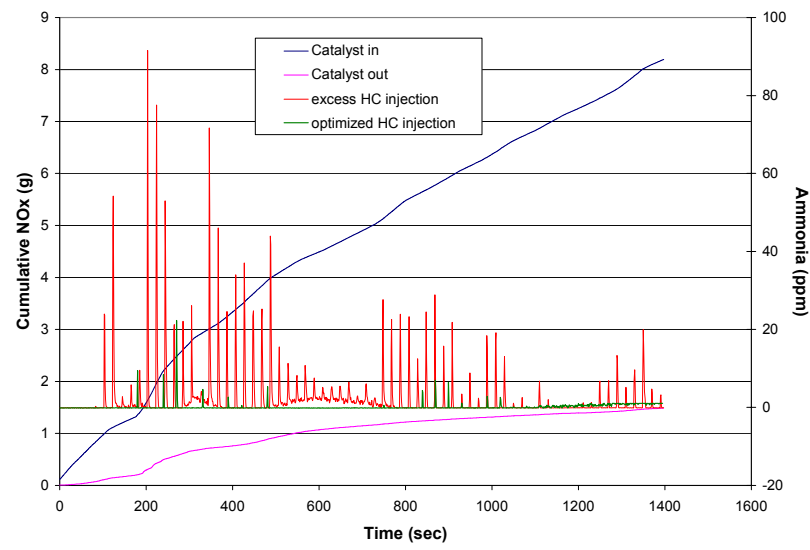

Fig. $10 \mathrm{NH}_{3}$ Slip from Aftertreatment system

This testing showed that $\mathrm{NH}_{3}$ does form over the adsorber but it seems to be a secondary reaction to $\mathrm{HC}$ combustion and NOx reduction. If $\mathrm{HC}$ is still left after these reactions, it may form $\mathrm{NH}_{3}$ if conditions are right for that reaction. So if the control strategy is well defined to avoid over injection, $\mathrm{NH}_{3}$ formation may not be a problem.

Based on the target AF ratio for these tests, the $\mathrm{O}_{2}$ in exhaust was supposed to be close to zero after each injection. However, the oxygen does not drop to the low levels in the exhaust always. It was noticed that the $\mathrm{NH}_{3}$ spike was higher every time the $\mathrm{HC}$ combustion efficiency was high (oxygen in exhaust was less). It was also noticed in this testing that $\mathrm{NH}_{3}$ formation was proportional to $\mathrm{HC}$ injection quantity. As can be seen in the figure, very little $\mathrm{NH}_{3}$ is formed when the $\mathrm{HC}$ injection is optimized. $\mathrm{NH}_{3}$ spikes are still seen around $200 \mathrm{sec}$ in the cycle. These spikes are believed to be due to the stored $\mathrm{HC}$ over the first 200 seconds.

\section{LOW TEMPERATURE LIGHT-OFF AND REDUCTANT SCREENING}

Progress has been made on the adsorber formulation development [1]. The engine test results indicate that the NOx conversion vs. temperature curve has extended the operation of catalysts by about 50 to $100 \mathrm{C}$ lower as compared to the previous formulations. However, due to diesel fuel oxidation limitations, the low temperature light-off of an adsorber may not be expected below $200 \mathrm{C}$. Two alternatives have been analyzed to improve low temperature conversion of NOx adsorbers, (1) using a reformer to generate reductants, which can operate at lower temperatures and (2) to raise exhaust temperatures so that diesel fuel may be used directly as the reductant. An analysis tool was used to compare the fuel economy penalty between the cases where a reformer is used vs. exhaust temperature enhancement. The reformer produces hydrogen and carbon monoxide, which are active reductants even at $180 \mathrm{C}$ while diesel is active only above $200 \mathrm{C}$. The reactor test results indicate that $\mathrm{H} 2$ is the best reductant, followed by a mixture of $\mathrm{H} 2$ and $\mathrm{CO}$, followed by $\mathrm{CO}$. Short straight chain (C4-C8) hydrocarbons are not good reductants for adsorber catalyst (Figure 11).

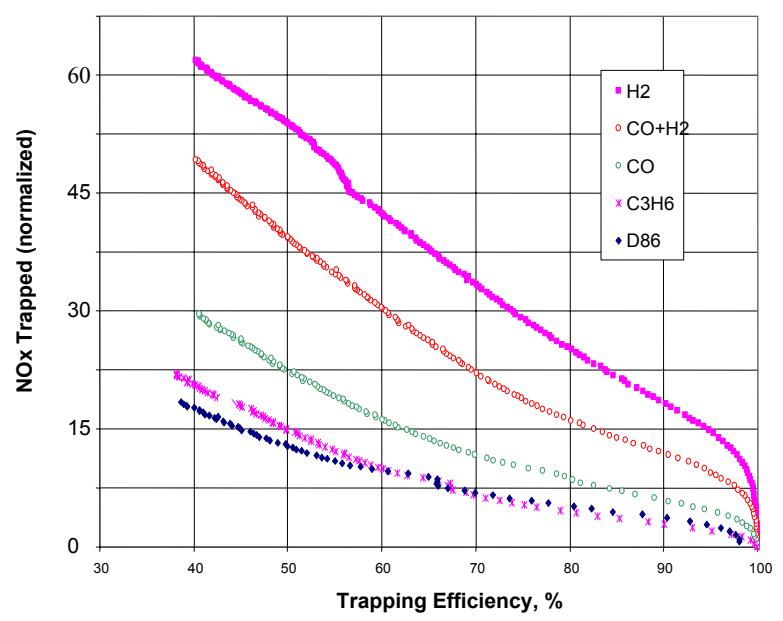

Fig. 11 Effectiveness of different reductants on adsorber trapping capacity

For low temperature operation of NOx adsorbers, either a reformer can be used or the exhaust temperature may be raised by $20 \mathrm{C}$. Analytical results show using the catalytic partial oxidation (CPO) reformer will require about $2 \%$ fuel penalty to keep it running, and the total fuel penalty for the reformer option will be almost $7 \%$ as compared to $5 \%$ for exhaust temperature enhancement [5].

Using a CPO reactor the feasibility of using diesel fuel to generate the syngas and use as the reductant was evaluated. The CPO was hooked upstream of the 
catalyst. During this initial testing Naphtha (Carbon Number chemistry from C7- C10) was used to generate the syngas. During the regeneration cycle the engine exhaust was bypassed $100 \%$ and only the reformate (syngas) flowed through adsorber catalyst. GC analysis showed $30 \% \mathrm{H} 2$ and $17 \% \mathrm{CO}$ in the dry reformate. A NOx conversion of greater than $90 \%$ was demonstrated for inlet exhaust temperatures ranging from $148 \mathrm{C}$ to $448 \mathrm{C}$.

\section{CATALYST DEGRADATION}

Catalyst durability is the most critical issue for current aftertreatment systems using NOx adsorber technology. Spectroscopic characterization of the inlet portion of catalyst samples following the time sequence of an engine test revealed important information related to catalyst deactivation. Deactivation of NOx adsorbers involves many pathways and S-poisoning is possibly the most recognizable one. The degradation pathways that have been identified under this program are summarized in Figure 12.

\begin{tabular}{|c|c|c|c|c|}
\hline \multicolumn{5}{|c|}{ Adsorber degradation mechanisms } \\
\hline & Chemical & Thermal & Mechanical & Capability/Tool \\
\hline Adsorption & $\begin{array}{l}\text { S poisoning (fuel/Aube) } \\
\text { Lube/ash poisoning } \\
\text { Carbonaceous deposits } \\
\text { (coking) } \\
\text { Condensation/solubility } \\
\text { of metal nitrate }\end{array}$ & $\begin{array}{l}\text { Pt \& Metal-Oxide } \\
\text { sintering }\end{array}$ & $\begin{array}{l}\text { Physical } \\
\text { breakage }\end{array}$ & $\begin{array}{l}\text { Surface Analysis } \\
\text { DRIFTS } \\
\text { Lube oil tests } \\
\text { Reactor }\end{array}$ \\
\hline Regeneration & $\begin{array}{l}\text { Residual nitrate } \\
\text { Physical/chemical } \\
\text { blockage of pores }\end{array}$ & $\begin{array}{l}\text { Pt-MO interactions } \\
\text { MO-support } \\
\text { interactions }\end{array}$ & & $\begin{array}{l}\text { SpaciMS } \\
\text { DRIFTS }\end{array}$ \\
\hline Conversion & $\begin{array}{l}\text { Poison-induced } \\
\text { reconstruction of } \\
\text { catalyst surface }\end{array}$ & Pt \& MO sintering & & $\begin{array}{l}\text { Surface Area } \\
\text { Platinum Dispersion }\end{array}$ \\
\hline Desulfation & Residual sulfate & $\begin{array}{l}\text { Pt \& MO sintering } \\
\text { Pore / surface changes }\end{array}$ & Thermal shock & $\begin{array}{l}\text { Reactor } \\
\text { Engine Tests }\end{array}$ \\
\hline
\end{tabular}

Figure 12 Catalyst Degradation Mechanisms

Surface changes on catalysts can be characterized using differential DRIFTS, a subtraction of the spectrum of the fresh sample from the spectrum of an aged sample. Both buildups and depletions are observed in differential DRIFTS. The assignment of the condensed hydrocarbons can be verified by Raman spectra between the fresh and the aged sample. For aged samples, the fluorescence comes from the aromatic residual of the condensed hydrocarbon species. The intensity ratio between these two carbon bands reflects the aromatic domain size. It is a good indicator of formation of coke precursor. Temporal buildups of nitrates, sulfates and hydrocarbons were also studied. Nitrate buildup seems to slow down after $200 \mathrm{hrs}$ of operation. Besides a rapid increase at the beginning, the sulfate buildup increases continuously in intensity with time. Further reactions of surface oxy-sulfur species to form pyro- or poly-sulfates may account for the continuous buildups. The overall buildups of hydrocarbons also grow with time. However, the nonuniformity of the burning of the injected fuel during operation gives rise to fluctuations in hydrocarbon deposit.

\section{CONCLUSIONS}

Results of extensive aftertreatment subsystem design and analysis to date indicate that the best NOx control approach for LDV and LDT applications is NOx adsorber technology. A greater than $84 \%$ combined NOx reduction efficiency is required to achieve 0.07 $\mathrm{g} / \mathrm{mile}$ NOx vehicle-out emissions. An $84 \%$ NOx conversion efficiency and 95\% PM conversion efficiency has been demonstrated with a breadboard low emission Cummins ISB engine and an adsorber/CPF exhaust configuration on a simulated FTP-75 emission cycle at about $7 \%$ total fuel penalty. Encouraging NOx conversion efficiency results were also obtained at ANL with the present EAS system. A NOx conversion efficiency of $99 \%$ can be obtained with a preconditioned catalyst. Without preconditioning a NOx conversion efficiency of $89 \%$ could be achieved at about $11.6 \%$ total fuel penalty for the FTP-72 cycle. The PM conversion was close to $100 \%$ and was beyond the detection capability of the measurement system at ANL.

With the lower exhaust temperatures encountered in Light Duty vehicle application, the improvement in NOx conversion efficiency over a wider exhaust temperature range has also been identified as a critical development task. Significant progress has been made on adsorber formulation development, extending the operation of the catalysts by 50 to $100 \mathrm{C}$ lower as compared to previous formulations.

Progress has also been made on NOx adsorber regeneration strategies reducing the fuel injection penalty by 40 to $50 \%$ compared to earlier tests. There is some $\mathrm{NH}_{3}$ production during adsorber regeneration but is not an issue if the $\mathrm{HC}$ injection is optimized. Heat release from $\mathrm{HC}$ injection for adsorber regeneration may be utilized to keep the CPF clean.

Throughout the project the emphasis has been on a fundamental understanding of aftertreatment technologies. Demonstrations have been focused on repeatable performance and development efforts have been directed towards technologies, which have a reasonable chance of meeting EPA anticipated regulations. Much has been accomplished to date, but much work remains in order to deliver the technology to marketplace.

\section{ACKNOWLEDGEMENTS}

Support for this work is provided by the Department of Energy (Contract DE-FC02-99EESOS77) and Cummins, Inc. The author would also like to express sincere appreciation to the colleagues $\mathrm{CZ}$ Wan and Howard Fang for their help in making this paper possible. 


\section{REFERENCES}

1. "Development of Advanced Aftertreatment Subsystem Technologies for CIDI Diesel Engines," Diesel Engine Emission Reduction Workshop, Robert C. Yu, Scott Cole, and Ken Howden, August 2001

2. "Employing Reactor Studies for the Research and System Development of Lean $\mathrm{NO}_{x}$ Traps," Diesel Engine Emission Reduction Workshop, Neal Currier, Matthew J. De Witt, Alex Yezerets, John Buglass, Geert Bakker, Joe Powell, Steve Cowan, Paul Weider, and C Z Wan, Portsmouth, VA, August 2001

3. "Impact of Sulfur on $\mathrm{NO}_{\mathrm{x}}$ Trap Catalyst activity Study of the Regeneration Conditions", SAE 982607, M. Guyon, F. Blejean, C. Bert, Ph. Le Faou, Oct. 1998.

4. "Effects of Sulfur on Performance of Catalytic Aftertreatment Devices", SAE 920557, Robert J. Farrauto and John J. Mooney, 1992.

5. "Effect of reductant on NOx adsorbers", Diesel Engine Emission Reduction Workshop, Rahul Mital, J. Dipchand, C.Z. Wan, Portsmouth, VA, August 2001.

6. Bailey, O., Dou, D. And Denison, G.W., "Regeneration Strategies for NOx Adsorber Catalysts", SAE972845, 1997. 